\title{
Mental Models in Deductive Reasoning
}

\author{
Juan A. García-Madruga1, Francisco Gutiérrez ${ }^{1}$, Nuria Carriedo ${ }^{1}$, \\ Sergio Moreno ${ }^{2}$, and Philip N. Johnson-Laird ${ }^{3}$ \\ ${ }^{1}$ National Open University (UNED) \\ ${ }^{2}$ University of Granada \\ ${ }^{3}$ Princeton University
}

\begin{abstract}
We report research investigating the role of mental models in deduction. The first study deals with conjunctive inferences (from one conjunction and two conditional premises) and disjunctive inferences (from one disjunction and the same two conditionals). The second study examines reasoning from multiple conditionals such as: If $e$ then $b$; If a then $\mathrm{b}$; If $\mathrm{b}$ then $\mathrm{c}$; What follows between a and $\mathrm{c}$ ? The third study addresses reasoning from different sorts of conditional assertions, including conditionals based on if then, only if, and unless. The paper also presents research on figural effects in syllogistic reasoning, on the effects of structure and believability in reasoning from double conditionals, and on reasoning from factual, counterfactual, and semifactual conditionals. The findings of these studies support the model theory, pose some difficulties for rule theories, and show the influence on reasoning of the linguistic structure and the semantic content of problems.

Key words: deductive reasoning, mental models, conditionals
\end{abstract}

En este trabajo presentamos varios estudios que investigan la construcción y manipulación de modelos mentales en el razonamiento deductivo. El primer estudio trata sobre inferencias conjuntivas (formadas a partir de una conjunción y dos condicionales) y disyuntivas (formadas a partir de una disyunción y los mismos dos condicionales). El segundo estudio examina la construcción e integración de modelos y el razonamiento a partir de problemas de condicionales múltiples como: Si e, entonces $b_{;}$Si $a_{1}$ entonces b; Si b, entonces c. ¿Qué se puede concluir entre a y b? El tercer estudio aborda la representación y el razonamiento a partir de los condicionales con a menos que y su comparación con los condicionales formulados mediante si, entonces; sólo si; y a menos que. Por último, brevemente, se presenta la investigación llevada a cabo sobre el efecto de la figura en el razonamiento silogístico, el efecto de la estructura y la credibilidad en los condicionales dobles, $y$ las diferencias en el razonamiento entre los condicionales fácticos, contrafácticos y semifácticos. Los resultados de estos estudios apoyan la teoria de los modelos mentales, plantean dificultades a las teorias de reglas y ponen de manifiesto la influencia sobre el razonamiento de la formulación lingüística, la estructura y el contenido semántico de los problemas.

Palabras clave: razonamiento deductivo, modelos mentales, condicionales

The research presented in this paper is part of two projects funded by the Spanish Ministry of Education and Science (PB94-0394 and PB98-0020-C03-01) and by a grant to the last author from the US National Science Foundation (Grant BCS-0076287) to study strategies in reasoning.

Correspondence concerning this article should be addressed to Juan A. García-Madruga, Dpto. de Psicología Evolutiva. Facultad de Psicología. UNED. 28040 Madrid (Spain). E-mail: jmadruga@psi.uned.es 
Deductive rcasoning is a mental process that leads from a set of premises to a valid conclusion, i.e., to a conclusion that must be true if the premises are true. As in other fields of human cognition, the study of deduction has grown exponentially during the last 35 years. Hence, the psychology of reasoning now provides a more precise and detailed knowledge about human deduclive ability and its limitations in different deductive inferences than it did three decades ago (e.g., see Evans \& Over, 1996). Unlike other areas of cognition, however, the increase in the research into deductive inference has not led to a concomitant growth in theoretical approaches. The deliberate search for " unified theories" has prevented the proliferation of mini-theorics of specific experimental paradigms. Hence, current studics can be considered within the framework of two main sorts of theory: theories based on formal rules of inference akin to those of logic (henceforth, rule theories) and theorics based on mental models (henceforth, model theories). There are other theories of deductive reasoning, but they do bave a narrower purview. In this article, we report some studics carried out by our research group in order to investigate the model theory. But, before we describe our research, we outline the two sorts of theory, because our experiments examine their contrasting predictions.

Rule theories have a long history going back to Piaget, and before him to the nineteenth century logician, George Boole. Recent rule theories follow their lead in postulating that human reasoning depends on formal rulcs of inference akin to those of logic (Braine, 1978; Braine \& O'Brien, 1991; Rips, 1983, 1994). Thesc tacit rules are used to develop a mental proof that a conclusion follows from the premises, and each step in the proof depends on a formal rule, that is, a rule that allows symbols to be rewritten solely in virtue of their form, not their content. As an example, consider the following inference:

If Carlos is in Salananca, then Elisa is in Albacete. Carlos is in Salamanca.

Therefore, Elisa is in Albacete.

According to rule theories, reasoners extract the underlying logical form of the premises:

If $p$ then $q$.
$p$.

Therefore, $q$.

They search their repertory of formal rules for one that can be applied to this logical form. The theories postulate the existence of well-known formal rule known as Modus Ponens (MP), which matches the form above. And so, there is a proof in a single step that the conclusion follows from the premises (Braine \& O'Brien, 1991; Rips, 1983, 1994). It is a fact that from any set of premises infinitely many valid conclusions follow, though most of them are trivial. Hence, all of the following conclusions follow:

\footnotetext{
If $p$ then $q$.

p.

Therefore, $p$.
}

Therefore, $p$ or $r$, or both

Therefore, $p$ or $r$ or s, or all.

And so on.

Only a logician or an insanc individual is likely to draw such conclusions, but they are valid, that is, they are true granted that the premises are true. One difficulty for rule theories is therefore to determine which particular conclusion individuals tend to draw. The theories accordingly tend to be framed in order to evaluate given conclusions rather than to account for the conclusions that individuals draw sportaneously.

The principal prediction of rule theories is that the difficulty of an inference depends on the number of inferential steps (each depending on a rule of inference) needed to draw the conclusion. The theories also allow, however, that the availability of a rule and the difficulty of applying it affect the difficulty of inferences. But, the theories rely on post hoc estimates of this factor from data gathered from experimental participants. In the case of the preceding example, the inference should be very easy because its derivation depends on a single step using a simple rule of inference.

Mental model theories postulate that human beings reason, not on the basis of form, but on the basis of content. They can construct mental models of situations both when they perceive a real event and when they understand discourse. The mental processes underlying reasoning are therefore semantic, not syntactic (Johnson-Laird, 1983, 2000; Johnson-Laird \& Byrnc, 1991; Polk \& Newell, 1995). The first step is to understand the meaning of the premises. The second step is to use this understanding, knowledge of the particular situation, and any pertinent general knowledge, to construct a mental model of each of the possibilities compatible with the premises. The third step is to formulate a conclusion based on these models - a conclusion that makes explicit in a parsimonious way something that was not asserted in any premise, or, if there is a given conclusion, to evaluate this conclusion with respect to the models.

The theory of mental models to which we adhere is based on three main assumptions (see Johnson-Laird, 2000). The first assumption relates possibilities, which lic at the heart of the theory, to models:

I. Each mental model represents a possibility. The model captures what is common to the different ways in which the possibility might occur.

An exclusive disjunction, such as:

Either there is a circle or there is not a triangle allows one possibility or the other, but not both. The assertion elicits models of two different possibilities, one of the presence of a circle, and one of the absence of a triangle:

0 $\neg \Delta$

where each line denotes a separate mental model, and the symbol " $\neg$ " denoles negation and so " $\rightarrow \Delta$ " denotes that there is not a triangle. Individuals list these two possibilities when they are asked to state what is possible given the 
assertion. Models can represent relations among threedimensional entities or abstract entities; they can be static or kinematic. They underlie visual images, though many components of models are not visualizable.

The second principle concerns the structure of mental models, which is akin to the structure of a picture or diagram:

2. A mental model is iconic, that is, its parts correspond to the parts of what it represents, and its structure corresponds to the structure of the possibility.

A major advantage of such a representation is that the inspection of an iconic representation reveals truths over and above those of the propositions that were used in its construction (Johnson-Laird, 1983, p. 136). Consider, for example, the following problem (from Byrne \& JohnsonLaird, 1989):

The cup is on the right of the spoon.

The plate is on the left of the spoon.

The knife is in front of the cup.

The fork is in front of the plate.

What's the relation between the fork and the knife?

The premises call for the model:

plate spoon cup

fork knife

which represents the entities as though they were arranged symmetrically on top of a table. The model yields the answer to the question:

The fork is on the left of the knife.

Hence, the iconic nature of the model yields a conclusion over and above the propositions used in constructing the model. This aspect of models contrasts with a representation based, say, on expressions in formal logic. The mere inspection of such a representation would yield no more than an inspection of the list of premises above. The iconic nature of models also yields a plausible prediction. When a description is consistent with more that one possibility, it calls for more than one model, and the task of making an inference is reliably harder (Byrne \& Johnson-Laird, 1989).

In order to reduce the processing load on working memory, mental models conform to a third principle:

3. The principle of truth: mental models represent what is true according to the premises, but by default not what is false.

This principle applies at two levels. At one level, mental models represent only the possibilities that are true given a premise, as do the models of the disjunction above. At a lower level, however, a model represents a clause in the premises only when it is true in the possibility. Again, in the preceding example, the first model represents explicitly what is true in that possibility, that is, there is a circle, but it does not represent explicitly what is false, that is, it is false that there is not a triangle, and so there is a triangle. Likewise, the second model represents explicitly that it is true that there is not a triangle, but it does not represent that it is false that there is a circle. The principle of truth postulates that individuals by default do not represent what is false. But, there are exceptions that overrule the principle. The theory postulates that information about what is false is held briefly in the working memory in the form of a mental footnote. If individuals retain these footnotes, they can construct fully explicit models of assertions. They can accordingly flesh out their mental models of the exclusive disjunction into the following fully explicit models:

$\begin{array}{rr}\mathrm{O} & \Delta \\ \mathrm{O} & \neg \Delta\end{array}$

These models represent in a fully explicit way the two possibilities referred to by the previous exclusive disjunction, and, as they illustrate, a true affirmative is used to represent a false negative proposition and a true negation is used to represent a false affirmative proposition. Yet, the principle of truth is the norm. It yields models that are parsimonious, because they do not represent what is false.

A conjunction, such as:

There is a triangle and a circle

yields a single mental model, corresponding to the single possibility compatible with the assertion:

$\mathrm{O}$

$\Delta$

A conditional assertion, such as:

If there is a circle, then there is a triangle has two models:

$\mathrm{O}$

$\Delta$

The first model represents the possibility in which the conditional's antecedent (there is a circle) and its consequent (there is a triangle) are both true. The second model, represented by the ellipsis, is a place-holder with no explicit content, which represents the possibilities in which the antecedent is false. Johnson-Laird and Byme (1991) adopted a cumbersome notation to represent the footnotes on such a model, but later introduced a more efficient representation in a computer implementation of the theory, which makes footnotes on mental models to indicate what is false in them. The implicit model is what distinguishes the mental models of conditionals from the mental models of conjunctions.

Individuals who retain the mental models can flesh out their representation into fully explicit models, corresponding either to those of a biconditional (if there is a circle then there is a triangle, and if there isn't a circle then there isn't a triangle):

$$
\begin{array}{rr}
0 & \Delta \\
0 & \neg \Delta
\end{array}
$$

or to those of a regular conditional (if there is a circle then there is a triangle and if there isn't a circle then there may, or may not, be a triangle):

$\begin{array}{rr}0 & \Delta \\ \neg O & \Delta \\ \neg 0 & \neg \Delta\end{array}$

Table 1 presents the mental models and the fully explicit models of propositions formed from the set of 
sentential connectives playing a major role in deductive reasoning. The conditional and biconditional propositions share the same mental models, but their mental footnotes differ and accordingly yield different fully explicit models. Mental models can represent discourse about real, hypothetical, or imaginary situations, and they can represent knowledge in long-term memory. But, the topic of the present paper is their role in deductive reasoning. If a conclusion holds in all the models of the premises, that is, it has no counterexamples, it is necessary given the premises. If it holds in a proportion of models, its probability is equal to that proportion, granted that the models represent equiprobable alternatives. If it holds in at least one model, it is possible given the premises. And if it holds in none of the models, it is impossible given the premises. The theory therefore unifjes deductive reasoning about necessity, probability, and possibility (Johnson-Laird, 2000).

The model theory makes predictions about the four traditional forms of inference based on conditionals (Evans, 1993; Johnson-Laird \& Byrne, 1991):

If $\mathrm{p}$ then $\mathrm{q}, \mathrm{p}$, therefore, $\mathrm{q}$. (modus ponens: $M P$ )

If $\mathrm{p}$ then $\mathrm{q}$, not- $\mathrm{q}$, therefore, not-p. (modus tollens: $M T$ )

If $\mathrm{p}$ then $\mathrm{q}, \mathrm{q}$, therefore, $\mathrm{p}$. (affinning the consequent premise: $A C$ )

If $\mathrm{p}$ then $\mathrm{q}$, not-p, therefore, not-q. (demying the antecedent presnise: $D A$ )

With $\mathrm{MP}$, the situation represented in categorical premise, $p$, corresponds to the first model of the conditional, which yields the conclusion, $q$, and so the inference should be easy. MT is another valid inference. Its categorical premise eliminates the explicit model of the conditional, and so it may seem that no valid conclusion can be drawn (a common response). But, if reasoners succeed in constructing fully explicit models, either of a biconditional or a regular conditional, the categorical eliminates all but the model: $\neg \mathrm{p} \neg \mathrm{q}$, and so the correct conclusion can be drawn. MT should be more difficult than MP, because it calls for the extra cognitive work of fleshing out the models and of holding them in working memory. $\mathrm{AC}$ and $\mathrm{DA}$ are valid for a biconditional interpretation, but invalid for a regular conditional interpretation. As Table 1 shows, the conditional interpretation allows the fully explicit possibility of: $7 \mathrm{p}$ q, which refutes both inferences. But, reasoners may draw the $\mathrm{AC}$ conclusion from the single explicit mental model of the conditional, whereas they cannot draw the DA conclusion from the mental models of the conditional. It follows that $\mathrm{AC}$ should be more frequent than DA.

MP is easier than MT, and both rule theories and the model theory account for the difference. But, Girotto, Mazzoco, and Tasso (1997) used the model theory to predict a surprising result. MT is easier when the categorical premise is presented first than when it is presented second. Presented first, it provides an initial negative model:

$$
\neg \mathrm{q}
$$

so that reasoners should be more likely to flesh out their models of the conditional to include the cases where the antecedent is false. Byrne and Tasso (1999) used the model theory to predict another surprising result. MT is drawn more often from counterfactual than from factual conditionals. A counterfactual of the form, If $p$ had happened then $q$ would have happened, calls for models of both the counterfactual situation ( $p$ ) and the factual

Table 1

The Mental Models and the Fully Explicit Models Based on the Major Sentential Connectives

\begin{tabular}{|c|c|c|c|c|}
\hline \multirow{2}{*}{$\frac{\text { Connective }}{p \text { and } q}$} & \multicolumn{2}{|c|}{ Mental models } & \multicolumn{2}{|c|}{ Fully explicit models } \\
\hline & $\mathrm{p}$ & $\mathrm{q}$ & $\mathrm{p}$ & $q$ \\
\hline \multirow[t]{2}{*}{ por else $q$} & $\mathrm{p}$ & & $\mathrm{p}$ & $\neg q$ \\
\hline & & q & $\neg \mathrm{p}$ & $q$ \\
\hline \multirow[t]{3}{*}{ por q. or both } & $\mathbf{p}$ & & $\mathrm{p}$ & $\neg \mathrm{q}$ \\
\hline & & $q$ & $\neg \mathrm{p}$ & $\mathrm{q}$ \\
\hline & $\mathrm{p}$ & $q$ & $\mathrm{p}$ & $q$ \\
\hline \multirow[t]{3}{*}{ If $p$ then $q$} & $p$ & $q$ & $\mathrm{p}$ & $q$ \\
\hline & & & $\neg \mathrm{p}$ & $q$ \\
\hline & & & $\neg \mathrm{p}$ & $\neg 9$ \\
\hline \multirow[t]{2}{*}{ If and only if $p$ then $q$} & $\mathrm{p}$ & $q$ & $\mathrm{p}$ & $q$ \\
\hline & & & $\neg p$ & $\neg \mathrm{q}$ \\
\hline
\end{tabular}

Note. The fully explicit models represent clauses that are false using negations that are true: " $\neg$ " denotes negation, and " ..." denotes a wholly implicit model. Each line represents a model of a possibility. 
situation ( $\neg p \neg q$ ) that the conditional presupposes. Formal rule theories predict neither phenomena.

A major prediction of the model theory is that the more models that reasoners have to construct, the more difficult the task should be. It should take longer and be more prone to error. This and other predictions have had an impact on research. But, the theory has also been much criticized (see number 16 of Behavioral and Brain Sciences, 1993; and Johnson-Laird, 2000, for a brief review of the most recent criticisms). One criticism is that the model theory is vague, untestable, and indistinguishable from theories based on formal rules of inference. Another criticism is that the theory has yet to give an account of the semantic content of the propositions. One aim of the present studies is to refute these criticisms. To that end, we report three main experiments, which concern respectively the difference between reasoning with conjunctions and reasoning with disjunctions, the integration of models of multiple conditionals, and reasoning from conditionals couched using unless. We also briefly present three other studies.

\section{Propositional Reasoning:}

Conjunctions and Disjunctions

Rule and model theories explain deductive reasoning in different ways, but both sorts of theory are able to account for many of the principal results in propositional reasoning, i.e., reasoning that hinges on the logical properties of such sentential connectives as if, and, and or. Hence, the crucial evidence concerns differences between the predictions of the two sorts of theory. A relevant study is Rips $(1990,1994)$ because it examined problems for which the predictions of theories diverge. As Table 2 shows, each problem in this study has three premises.
The first premise is either a conjunction or a disjunction, and the remaining premises are conditionals. The participants in the study had to evaluate whether or not the given conclusion was necessary, responding either "Yes" , or else "No." According to the model theory, problem (1) calls for a single mental model of the first premise (a conjunction), and then the meaning of the two conditionals can be integrated to yield the single model:

$$
\mathrm{p} \quad \mathrm{q} \quad \mathrm{r}
$$

This model yields the conclusion, $R$, which is necessary because it holds in all the models - in this case, the single model- of the premises. In contrast, problem (2) calls for at least two mental models of the first premise (a disjunction), and the meanings of the two conditionals allow this model to be updated as follows:

$$
\begin{array}{lll}
\mathbf{p} & \mathbf{r} \\
\mathbf{r} & \mathbf{r}
\end{array}
$$

The same valid conclusion, $R$, follows, but the task should be harder because reasoners have to construct and to hold in working memory at least two models of the premises. The process of constructing mental models from such premises has been implemented in a computer program. The program also yields the fully explicit models of the premises, which for the present problem are:

$$
\begin{array}{rrr}
p & \neg \mathrm{q} & \mathrm{r} \\
\mathrm{p} & \mathrm{q} & \mathrm{r}
\end{array}
$$

Because more models imply more work, the theory accordingly predicts that problem (1), which calls for a single mental model, should be harder than problem (2), which calls for at least two models. The theory makes the same prediction for problems (1') and (2'). In sum, the conjunctive inferences should be easier than disjunctive ones.

According to rule theories, the conjunctive problems call for the application of two rules drawn from the basic set of inference schemas posed by the main theories (Braine, 1990;

\begin{tabular}{|c|c|c|c|}
\hline & & & Rules \\
\hline \multirow[t]{7}{*}{ One-model problems } & 1. & $1^{\prime}$ & Forward And Elimination \\
\hline & $p$ and $q$ & Not-p and not-q & $P$ AND Q \\
\hline & If $p$ then $r$ & If not-p then $r$ & $\mathbf{P}$ \\
\hline & If $q$ then $r$ & If not-q then $r$ & Forward IF Elimination \\
\hline & & & IF P THEN R \\
\hline & $r$ & $r$ & $\underline{\mathbf{P}}$ \\
\hline & & & $\mathbf{R}$ \\
\hline \multirow[t]{6}{*}{ Multiple-model problems } & 2. & 2 & \\
\hline & $p$ or $q$ & Not-p or not-q & Forward Dilemma \\
\hline & If $p$ then $r$ & If not-p then $r$ & P OR Q \\
\hline & If q then $r$ & If not $q$ then $r$ & IF P THEN R \\
\hline & & & IF O THEN R \\
\hline & $r$ & $r$ & $\mathbf{R}$ \\
\hline
\end{tabular}

Table 2

The Problems Used in Rips (1990), and PSYCOP's Rules (Rips, 1994) to Solve Them 
Braine, Reiser, \& Rumain, 1984; Rips 1983, 1994). For instance, in Rips's (1994) most recent PSYCOP (short for Psychology of Proof) system for logical reasoning, reasoners need to apply the forward $A N D$ and $I F$ elimination rules (see Table 2). But, for the disjunctive problems, the rule theories postulate a single rule that allows the valid conclusion to be reached directly, that is, the Forward Dilemma rule. You might suppose that the rule theories make the opposite prediction to the model theory, because the conjunctive problems call for the application of two rules whereas the disjunctive problems call for the application of only one rule. However, according to Rips (1994), the Dilemma rule is "somehow harder" to apply: It calls for the coordination of three premises, whereas the rules to be applied to the conjunctive inferences call only for the coordination of one or two premises. Rips accordingly concludes: "There is no reason to think that one of these methods should be much easier than the other" (Rips, 1994, pp. 368-369). In other words, he argues that PSYCOP does not predict any difference in difficulty between the two sorts of problem. Rips (1990) found no significant difference between conjunctive and disjunctive problems. The difference between negative conjunctive and negative disjunctive problems, however, was in the direction predicted by the model theory, even though it was only marginally significant $(p<.10)$. Rips $(1990)$ accordingly took the results to corroborate his PSYCOP theory.

In a series of experiments, the present authors reexamined the conjunctive and disjunctive inferences (GarcíaMadruga, Moreno, Carriedo, Gutiérrez, \& Johnson-Laird, 2001). Experiment 1 compared inferences in which the participants evaluated given conclusions, as in Rips's (1990) original task, with inferences in which the participants drew their own conclusions from the premises. Rule theories do not predict any significant difference between the two tasks, because reasoners should use the same rules in both of them. But the model theory predicts that the reasoners' strategies are likely to differ between the two tasks. In the evaluation task, the reasoners can work backwards from the given conclusion. But, in the construction task, there is no given conclusion, and so this strategy cannot be used. Reasoners must generate a conclusion. It follows that the constructive task should be harder than the evaluative task. (A more detailed analysis of the possible strategies is presented in García-Madruga, Moreno Ríos, Carriedo, \& Gutiérrez., 1999; García-Madruga et al., 2001).

Experiment 2 was a replication of the previous experiment, except that the premises were presented in a different order: The two conditional premises occurred before the conjunctive or disjunctive premise, which was presented last. According to the rule theories, this change should have no effect on performance. But, according to the model theory, when the two conditional premises occur first, they call for the models:

$$
\text { p }
$$

$$
\begin{array}{cc}
\mathrm{q} & \mathrm{r} \\
\ldots &
\end{array}
$$

And these models preoccupy working memory during the processing of the third premise, and so the difference between the conjunctive and the disjunctive problems should be enhanced. The prediction is analogous to the effect of order on MT, where the inference should be harder when the conditional occurs first than when it occurs second (Legrenzi, Girotto, \& Johnson-Laird, 1993, and for an experimental corroboration Girotto, Mazzoco, \& Tasso, 1997).

Table 3 presents the results of Experiments 1 and 2. In Experiment 1 , the evaluation task did not yield any difference between the conjunctive and disjunctive problems. It therefore replicated Rips's (1990) results. But the constructive task showed that the conjunctive problems yielded a significantly greater percentage of correct conclusions, both for the affirmative and the negative problems (Wilcoxon tests, $z=2.24, p=.02$, one-tailed, and $z=2.35, p<.01$, one-tailed, respectively). As the table shows, the conjunctive problems are at ceiling in both conditions, whereas the disjunctive problems show poorer performance in the constructive condition. In Experiment 2, the presentation of the conditionals before the conjunction or disjunction did not have a dramatic effect on overall difficulty (at least in comparison with Experiment $i$-a comparison that is not strictly valid, because it is between two different

Table 3

\begin{tabular}{|c|c|c|c|c|c|c|c|c|}
\hline & \multicolumn{4}{|c|}{$\%$ Correct Affirmative Problems } & \multicolumn{4}{|c|}{ \% Correct Negative Problems } \\
\hline & \multicolumn{2}{|c|}{$\begin{array}{l}\text { Rips's Order } \\
\text { Experiment } 1\end{array}$} & \multicolumn{2}{|c|}{$\begin{array}{l}\text { Inverse Order } \\
\text { Experiment } 2\end{array}$} & \multicolumn{2}{|c|}{$\begin{array}{l}\text { Rips's Order } \\
\text { Experiment } 1\end{array}$} & \multicolumn{2}{|c|}{$\begin{array}{l}\text { Inverse Otder } \\
\text { Experiment } 2\end{array}$} \\
\hline & Evaluation & Construction & Evaluation & Construction & Evaluation & Construction & Evaluation & Construction \\
\hline Conjunctive problems & $\begin{array}{c}94.2 \\
(89.2)\end{array}$ & 97.4 & 100 & 95.8 & $\begin{array}{c}88.5 \\
(94.6)\end{array}$ & 92.3 & 100 & 93.7 \\
\hline Disjunctive problems & $\begin{array}{c}86.5 \\
(89.2)\end{array}$ & 76.9 & 77.3 & 81.3 & $\begin{array}{c}82.7 \\
(81.1)\end{array}$ & 66.7 & 79.6 & 77.1 \\
\hline
\end{tabular}

The Percentages of Correct Responses by Type of Task and Order Condition in Garcia-Madruga et al.'s (2000) Experiments 1 and 2

Note. Results obtained by Rips (1990) are in brackets. 
experiments). But, in this case, the conjunctive problems were significantly easier than the disjunctive problems both in the evaluation task and the construction task. In all the groups, the differences were significant both for affirmative and negative problems (Wilcoxon tests with $p$ values ranging from $p<.05$ to $p<.005$ ).

Experiment 3 made a direct comparison of the two orders of presenting the premises in an evaluation task. Unlike the previous experiments, the premises were presented one at a time on a computer screen, and we recorded both the times to read the premises, and the latencies of the participants' responses to the given conclusions. Table 4 presents the results. The overall times to process the problems were faster for the conjunctive problems than for the disjunctive problems (Wilcoxon test, $z=2.07, p=.02$, one-tailed). Likewise, in general, the times taken to read the premises were faster for conjunctive problems than for disjunctive problems. For the latencies to respond cortectly, the premises presented with the conditionals last (Rips"s 1990 original order) showed no significant difference between conjunctive and disjunctive problems, but this difference was significant for premises presented with the conditionals first.

In general, the results corroborated the model theory and ran counter to formal rule theories. The conjunctive problems call for the construction of one model, whereas the disjunctive problems call for more than one model. Rule theories predict either absence of differences or differences in the opposite direction. It is noteworthy that no differences in the opposite direction to the predictions of the model theory occurred in any of the studies, and only in the particular conditions of Rips's (1990) original study did the differences fail to reach significance, perhaps because of a ceiling effect. The moral is that there are experiments that distinguish between the predictions of the two theories, and that in the present case they support the model theory.

\section{Models of Multiple Conditionals}

Another reasoning task has enabled us to contrast the rule and model theories. In the "multiple conditionals" task, reasoners are given a series of premises that are each a conditional, and they have to draw a conclusion, if possible, interrelating two of the clauses that occur in the premises. In the following example, the three premises yield a direct transitive chain from $e$ to $c$ :

$$
\begin{aligned}
& \text { If } e \text { then } a \\
& \text { If a then } b \text {. } \\
& \text { If } b \text { then } c \text {. }
\end{aligned}
$$

What follows between $a$ and $c$ ? [Answer: If a then $c$.]

The following problem is very similar, but has a different initial premise:

If $e$ then $b$.

If $a$ then $b$.

If $b$ then $c$.

What follows between $a$ and $c$ ? [Answer: If a then $c$.]

Rule theories predict that the conclusion is drawn in an identical way for the two sorts of problem. Reasoners ignore the first premise, and then use two rules of inference: modus ponens (MP, as described earlier), and the rule of conditional proof, which allows reasoners to make a supposition or assumption, $P$, and then if they reach a conclusion, $Q$, to discharge the supposition by drawing a conditional conclusion: If $P$ then $Q$ (see Braine, 1978; Braine \& O'Brien, 1991; Rips, 1983, 1994). The derivation of the conclusion accordingly proceeds as follows for both problems 1 and 2 :
a [A supposition, using CP]
$b \quad$ [MP applied to the previous line and the second premise]
$c \quad$ [MP applied to the previous line and the third premise]
If $a$ then $c$ [Discharging the supposition using CP]

It follows that there should be no reliable difficulty between the two sorts of problem.

In contrast, the model theory predicts that reasoners should construct mental models of the set of premises. For problem 1, they should construct the following sequence of models (as does the computer program implementing the theory), which take into account each successive premise:

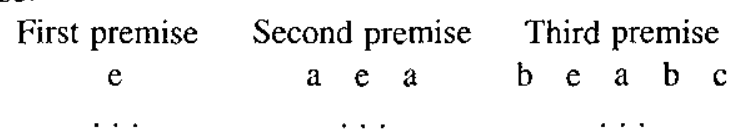

The final model yields the conclusion: if $a$ then $c$. Problem 2, however, calls for the construction of two explicit mental models:

Table 4

The Mean Reading Times of the Premises, the Correct Response Latencies, and the Overall Times (in Seconds) in Experiment 3

\begin{tabular}{llccc}
\hline & & Premise reading times & Response latencies & Overall times \\
\hline Conditionals last & Conjunctive problems & 9.52 & 2.87 & 22.51 \\
& Disjunctive problems & 11.62 & 3.78 & 26.61 \\
Conditionals first & Conjunctive problems & 8.54 & 3.04 & 25.72 \\
& Disjunctive problems & 8.38 & 6.02 & 28.97 \\
\hline
\end{tabular}




\begin{tabular}{|c|c|c|}
\hline First premise & Second premise & Third premise \\
\hline $\mathrm{e}$ & $b \quad \mathrm{e} b$ & e b c \\
\hline & $a \quad b \quad a$ & b c \\
\hline
\end{tabular}

The resulting models yield the same conclusion as before: If a then $c$. In this case, however, the two explicit mental models place a greater load on working memory, and so the inference should be harder. Once again, the two sorts of theory make different predictions about reasoning.

In order to examine the contrasting predictions of the two theories, we carried out several experiments (Gutiérrez Martínez, García-Madruga, Johnson-Laird, \& Carriedo López, 2002). We report one such study, which we refer to here as Experiment 4, in which we used problems similar to the ones above, except that they had four premises instead of three (see Table 5). Problem 3 in the table called for the construction of three explicit mental models, and so the theory predicts that it should be still harder. In order to balance responses, there were also filler items to which the correct response was " nothing follows." The participants were postgraduates from several universities, and we tested them individually using a computer-implemented procedure (Mac-Laboratory Reaction Time). The participants acted as their own controls and carried out two instances of each problem, working under their own control. The contents of the problems concerned imaginary recipes and referred to meals and cooking ingredients. As Table 5 shows, the rule theory predicts that problem 3 should be easier than the other two problems, because its derivation is shorter. The model theory, however, predicts a trend of increasing difficulty over the three problems: Problem I should be easier than problem 2, which in turn should be easier than problem 3.

The one-model problems yielded $90 \%$ correct conclusions, the two-model and three-model problems both yielded $72.5 \%$ correct conclusions, and the difference between the one-model and the multiple-model problems was significant (Wilcoxon test, $T=3, p=.025$, one-tailed). This pattern of results was typical of the other experiments. It is compatible with the model theory, but quite contrary to the predictions of the rule theories (see the lengths of the formal derivations in Table 5).

Figure 1 presents the reading times for the premises and the mean latencies of response. The reading times for the first and second premises did not differ significantly from one sort of problem to another. The reading time for the third premise, however, was significantly longer for

Table 5

The Three Sorts of Multiple Conditional Problem in Experiment 4, the Fomal Derivations of Their Conclusions, and the Mental Models of the Premises

\begin{tabular}{|c|c|c|c|}
\hline Problems & \multicolumn{2}{|c|}{ Formal rules of derivation } & Mental models \\
\hline If e then $a$. & 5 lines: & & One mental model: \\
\hline If a then $b$. & a & [Supposition] & \\
\hline If b then $c$ & $b$ & {$[\mathrm{MP}]$} & e a b $c d$ \\
\hline If $c$ then $d$. & c & {$[\mathrm{MP}]$} & . . \\
\hline What follows between a & d & {$[\mathrm{MP}]$} & \\
\hline and $\mathrm{d}$ ? [If a then $d$.] & If a then $d$ & {$[\mathrm{CP}]$} & \\
\hline If e then $b$ & 5 lines: & & Two mental models: \\
\hline If a then $b$. & a & [Supposition] & $e b c d$ \\
\hline If $b$ then $c$. & $\mathrm{b}$ & {$[\mathrm{MP}]$} & $a b c d$ \\
\hline If c then $d$ & $\mathrm{c}$ & {$[\mathrm{MP}]$} & . . \\
\hline What follows between & $d$ & {$[\mathrm{MP}]$} & \\
\hline a and $d$ ? [ lf a shen $d]$. & If a then d & {$[C P]$} & \\
\hline If e then $b$. & 4 lines: & & Three mental models: \\
\hline If a then $b$. & a & [Supposition] & \\
\hline If $c$ then $b$. & $\mathrm{b}$ & {$[\mathrm{MP}]$} & e bd \\
\hline If $b$ then $d$ & $d$ & {$[\mathrm{MP}]$} & a b d \\
\hline What follows between & If a then $d$ & {$[\mathrm{CP}]$} & c bd \\
\hline $\mathrm{a}$ and $\mathrm{d}$ ? [If $a$ then $d$ ] & & & . . \\
\hline
\end{tabular}

Note: The filler problems were invalid versions of problems 2 and 3 in which the question was about two unrelated items (What follows between a and $e$ ?). The correct answer was: "Nothing follows." 


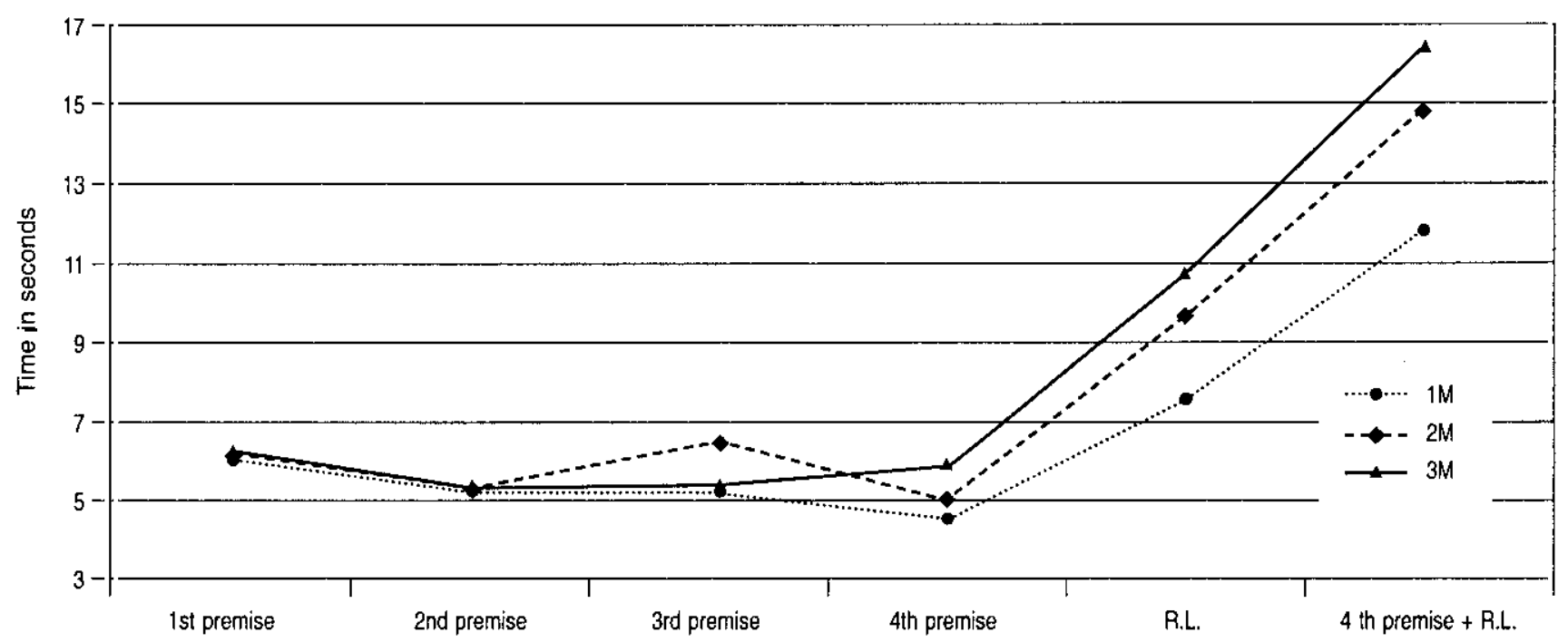

Figure I. Premise reading times and response latencies (in seconds) in Experiment 4 with multiconditionals.

the two-model problems than for the other sorts of problem. The reading times for the fourth premise and the response latencies show a trend with one-model problems faster than two-model problems, which in turn are faster than three-model problems. When we combine the reading time of the fourth premise with the latency of response, the results corroborate the effect of number of models: One-model problems (11.99 seconds) were dealt with faster than two-model problems (14.75 seconds; Wilcoxon test, $T=14, p<.01$, one-tailed), which were faster than three-model problems (16,29 seconds; Wilcoxon test, $T=20, p=.025$, one-tailed). This trend was repeated consistently in our other experiments. In sum, the difference caused by the need to process multiple models increases over the premises, which is compatible with the increasing load of multiple models on working memory. In contrast, rule theories make no specific predictions about the reasoning process: The reasoners' task is to extract the logical form of the relevant premises, and then to apply formal rules of inference. This task should be slightly easier with three-model problems, because they have a shorter derivation.

The increase in reading time for the third premise in the two-model problems can be attributed to the mental processes that these problems require. With the one-model and three-model problems, the third premise calls only for repeating an operation that has already been performed for the second premise: for the one-model problems, the integration of a new element; and for the three-model problems, the creation of a new model because direct integration is impossible. But, with the two-model problems, a new operation is necessary: The element, $c$, has to be integrated into the two independent models constructed previously. This multiple integration evidently places a load on working memory. Thereafter, the reading time for the fourth premise and the latency to respond appear to reflect the number of models that have to be held in working memory (see also García-Madruga, Moreno, Carriedo, \& Gutiérrez, 2000).

One complication is that different individuals may develop different strategies for coping with these problems. One such strategy, which was formulated by Walter Schaeken (personal communication) for spatial reasoning problems, is that reasoners may not construct all possible models, but instead seek to tag a single model with alternative possibilities. Reasoners know that the fourth premise is that last one before the final question, and so another plausible strategy to minimize the processing load on working memory is to suspend integration until further information about the problem is provided by the question itself (see Gutiérrez, García-Madruga, Carriedo, \& Moreno, 2000). These possibilities call for further investigation, particularly studies that call for the participants to think aloud as they reason. Such studies have indeed shown that different individuals develop different strategies (Van der Henst, Yang, \& JohnsonLaird, in press).

\section{Mental Models and Four Sorts of Conditional}

The study of conditional reasoning has focused on conditionals of the form: if $p$ then $q$. Other forms of sentence, however, can be interpreted as conditionals depending on their content and context (Johnson-Laird \& Byme, in press). The "contrapositive" assertion: if not $q$ then not $p$, with neutral contents is logically equivalent to if $p$ then $q$. The " only if" assertion: $p$ only if $q$, with neutral contents is logically equivalent to if $p$ then $q$. And the "unless" assertion: not $p$ unless $q$, is also logically equivalent to if $p$ then $q$. Philosophers have traditionally considered assertions 
of the form not $p$ unless $q$ to be semantically equivalent to if not $q$ then not $p$ (e.g., Quine, 1972; Reichenbach, 1947). Geis (1973) argued that a more accurate paraphrase was not $p$ except if $q$, but Fillenbaum $(1976,1986)$ argued instead that a more accurate paraphrase was $p$ only if $q$, because the meaning of both assertions makes the negative possibility more salient. Wright and Hull $(1986,1988)$ compared not $p$ unless $q$ with if not $q$ then not $p$ in a series of experiments in which $p$ referred to an action and $q$ referred to a condition. Their participants had more difficulty reasoning with unless assertions than with the conditionals. They accordingly concluded that the two sorts of assertion have different mental representations.

According to rule theories, the reasoning process with the four sorts of conditional depends on transforming them, where necessary, into conditionals of the if-then sort (e.g., Braine, 1978). The transformation for only if assertions and for unless assertions yields if not $q$ then not $p$. Thereafter, the standard rules of inference for conditionals can be applied to these transformations. In contrast, the model theory postulates that only if and unless assertions have two explicit mental models, because their meanings make the negative cases salient (Fillenbaum, 1976, 1986). They differ only in which of the two models is more salient. But, all four assertions have the same fully explicit models corresponding to those for if-then assertions (see Table 1). Table 6 summarizes the mental models and the formal transformations for the four sorts of conditional.

Each of the four sorts of conditional can be paired with an affirmation or denial of a categorical premise in order to yield the four sorts of inference: MP, MT, AC, and DA (see Table 6). Rule theories rely on the same inferential steps for MP, and for MT, regardless of the form of the conditional, and according to their derivations MP should be easier than MT. Similarly, given the mental translation of the propositions, the same prediction should hold for $p$ only if $q$ and not $p$ unless $q$ (see Table 6). The model theory also predicts that MP should be easier than MT for if $p$ then $\dot{q}$ and if not $q$ then not $p$. But, $p$ only if $q$ and not $p$ unless $q$ both have two explicit mental models, and these models allow a direct inference of both MP and MT without the need to flesh out into fully explicit models. The consequences are twofold: First, the difference in difficulty between the two inferences should disappear; and second MP should be harder for these assertions than ordinary conditionals, because working memory is preoccupied by two mental models. Both predictions have been corroborated (see Johnson-Laird, Byme, \& Schaeken, 1992; cf. Evans, Clibbens, \& Rood, 1995).

In one of their experiments, which we refer to here as Experiment 5, García-Madruga, Carriedo, Moreno, Gutiérrez and Schaeken (2002) examined reasoning with the four sorts of conditional in a response evaluation task. The content of the problems referred to letters on one side of a card and numbers on the other side of the card, for example: If there is an $A$ on one side then there is a 4 on the other side. The experiment was run under computer control. After the participants had read the instructions and carried out some practice trials, the experiment proper began. On each trial, one of the four sorts of conditionals appeared on the computer screen. The participants read the sentence and then pressed the space bar. This response led to the presentation of the categorical premise. When the participants had read it, they pressed the space bar again, and a putative conclusion appeared on the screen. The participants had to decide whether the conclusion was necessarily true given the premises, necessarily false given the premises, or neither, and they made their response by pressing one of three different keys.

Table 7 presents the percentages of responses endorsing the four sorts of inference and the combined latencies to read the categorical premise and to respond. We focus here on two principal resuits pertinent to the contrast between rule and model theories. First, as the model theory predicts:

Table 6

The Mental Models for Four Sorts of Conditional, and the Possible Formal Transformations of the Conditionals According to Braine's (1978) Rule Theory

\begin{tabular}{|c|c|c|c|}
\hline Conditionals & \multicolumn{2}{|c|}{ Mental models } & Formal transformations \\
\hline If $p$ then $q$ & $\mathrm{p}$ & $q$ & - \\
\hline If not $q$ then not $p$ & $\neg \mathrm{q}$ & $\neg \mathrm{p}$ & - \\
\hline$p$ only if $q$ & $\begin{array}{r}\mathrm{p} \\
\neg \mathrm{p}\end{array}$ & $\begin{array}{r}q \\
\neg q\end{array}$ & $\begin{array}{l}\text { Not } p \text { if other than } q \\
\text { If not } q \text { then not } p\end{array}$ \\
\hline Not $p$ unless $q$ & $\neg \mathrm{p}$ & $\begin{array}{r}\neg q \\
q\end{array}$ & $\begin{array}{l}\text { Not } p \text { if not } q \\
\text { If not } q \text { then not } p\end{array}$ \\
\hline
\end{tabular}


Table 7

The Percentages of Inferences and Their Latencies in Seconds (in Brackets) for Each Sort of Conditional Sentence and Each Form of Inference in Experiment 5: $M P, A C, M T, D A$

\begin{tabular}{lcccc}
\hline & & & & Inference \\
\cline { 2 - 5 } Conditional Sentence & $\begin{array}{c}p \\
\text { Therefore, } q\end{array}$ & Not $p$ & $q$ & Not $q$ \\
Therefore, not $q$ & Therefore, $p$ & Therefore, not $p$ \\
\hline If $p$ then $q$ & MP: $98(2.5)$ & DA: $63(5.0)$ & AC: $75(3.9)$ & MT: $78(5.5)$ \\
If not $q$ then not $p$ & MT: $63(5.6)$ & AC: $64(5.3)$ & DA: $66(4.6)$ & MP: $96(3.4)$ \\
$p$ only if $q$ & MP: $94(3.3)$ & DA: $69(4.7)$ & AC: $89(2.9)$ & MT: $90(3.9)$ \\
Not $p$ unless $q$ & MP: $76(4.2)$ & DA: $56(5.4)$ & AC: $86(3.0)$ & MT: $86(4.6)$ \\
\hline
\end{tabular}

Note $\mathrm{MP}=$ Modus Ponens $; \mathrm{AC}=$ Affirming the consequent; $\mathrm{MT}=$ Modus Tollens; $\mathrm{DA}=$ Denying the antecedent.

MP is easier than MT for the two conditionals (if $p$ then $q$, if not $q$ then not $p$ ), but the difference disappears for the other two assertions ( $p$ only if $q$, not $p$ unless $q$ ). The interaction was significant both for accuracy and latency. It is, of course, contrary to the predictions of the rule theory.

Second, as Table 7 shows, AC conclusions occurred more often and more rapidly for only if and unless assertions than for the other two sorts of conditional. (These results were all statistically significant, but we spare readers the details.) This pattern for only if has been demonstrated before (Evans, 1977, 1993; Evans \& Beck, 1981; Evans, Clibbens, \& Rood, 1995). What they also corroborate is Evans and Beck's (1981) hypothesis that $p$ only if $q$ and not $p$ unless $q$ call for models in which the order of terms is reversed:

$$
\begin{aligned}
& p \text { only if } q \\
& \mathrm{q} p \\
& \neg \mathrm{q} \neg \mathrm{p} \\
& \text {... }
\end{aligned}
$$

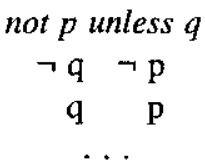

Conditionals based on unless have some idiosyncratic properties. One inference that is particularly difficult is DA:

$$
\text { Not } p \text { unless } q \text {. }
$$

Not $p$.

Therefore, $q$.

It occurs less often and more slowly than with the other sorts of conditional (cf García-Madruga, Carriedo, Moreno, Gutiérrez, \& Schaeken, 2002; Schaeken, García-Madruga, \& D'Ydewalle, 1997). A small but noticeable proportion of participants, in fact, drew the conclusion: $g$. According to Schaeken, et al. (1997), the response results from a superficial " matching strategy" rather than from a proper interpretation of the premises: The minor premise, not $p$, matches the first clause in the unless assertion, and so individuals draw a conclusion that matches the second clause.

Such idiosyncrasies, and the difficulty of coping with unless, might be ameliorated when the content of problems refers to common events in daily life, such as conditional warnings and threats (see Fillenbaum, 1976, 1986), for example:

You will not pass the exam unless you study more. Do not travel by car unless you take along chains.
In a further study, Experiment 6, we examined participants' reasoning with the same four propositions from the previous experiment but with four different sorts of content (Carriedo, Garcia-Madruga, Gutiérrez, \& Moreno, 1999). The first contents were abstract, that is, as in the previous experiment, the assertions referred to letters and numbers on cards, for example,

There isn't an A on one side unless there is an I on the other side.

The second contents were neutrai: The assertions referred to the co-occurrence of two events but with no causal relation between them, for example:

I don't drink wine unless I eat meat.

The third contents were everyday warnings:

Don't use a welding torch unless you wear protective eye covering

The fourth contents were everyday threats:

Don't make more spelling mistakes unless you want to repeat the sentence ten times

The participants had to write down their conclusions to the four sorts of inference, or to respond that there was no conclusion.

Table 8 presents the percentages of inferences for the four sorts of contents for the unless assertions. Although MT inferences tended to be easier than MP inferences (except for the arbitrary content), the difference was not significant for any of the contents. There was a similar tendency for $\mathrm{AC}$ to be easier than $\mathrm{DA}$, which was significant for the abstract materials (Wilcoxon test, $z=$ $2.49, p=.02$, two-tailed). Although the matching response to DA inferences occurred for abstract (14\%) and neutral contents $(8 \%)$, it did indeed disappear with the threats and warnings. This phenomenon suggests that the everyday contents heiped reasoners to make a proper interpretation of the premises. Finally, the threats yielded a greater proportion of inferences, which suggests that the participants treated them as biconditional, that is, compatible with only two possibilities, and so all four sorts of inference are valid, and there is no possibility of the form: $\neg \mathrm{p} \mathrm{q}$, to block $\mathrm{AC}$ and $\mathrm{DA}$. 
Table 8

The Percentages of Inferential Responses for "Unless" Conditionals for Each Sort of Content and Each Form of Inference in Experiment 6. The Percentages of Correct Responses "There is no Conclusion" are Shown in Parentheses for the DA and $A C$ hiferences

\begin{tabular}{lcccc}
\hline & & \multicolumn{3}{c}{ Inference } \\
\cline { 2 - 5 } & $\mathrm{MP}$ & $\mathrm{DA}$ & $\mathrm{AC}$ & $\mathrm{M}$ \\
Content & $p$ & Not $p$ & $q$ & Not $q$ \\
Therefore, $q$ & Therefore, not $q$ & Therefore, $p$ & Therefore, not $p$ \\
\hline Abstract & 75 & $44(42)$ & $81(14)$ & 72 \\
Neutral & 72 & $61(31)$ & $58(33)$ & 81 \\
Warnings & 77 & $58(39)$ & $64(36)$ & 81 \\
Threats & 81 & $89(8)$ & $94(0)$ & 94 \\
\hline
\end{tabular}

Note. $\mathrm{MP}=$ Modus Ponens $; \mathrm{DA}=$ Denying the antecedent; $\mathrm{AC}=$ Affirming the consequent; $\mathrm{MT}=$ Modus Tollens.

\section{Three Recent Studies}

In this section, we examine three phenomena: the figural effect in syllogistic reasoning, the effects of content on reasoning from two conditional premises (" double conditionals"), and reasoning from counterfactual conditionals. In each case, the results are relevant to the theory of mental models.

\section{Figural Effects in Syllogistic Reasoning}

Syllogisms are deductive arguments made up of two premises and a conclusion in which each assertion is based on a quantifier, such as all, some, or none. A typical syllogism has the following form:

\section{All the $A$ are $B$.}

None of the $B$ is $C$

Therefore, none of the $A$ is $C$.

where $A$ and $C$ are the end terms and so occur in the conclusion, and $B$ is the middle-term that occurs in both premises. In the traditional formalization of syllogisms, there are four sorts of assertion known as " moods" :

\section{All $X$ are $Y$.}

Some $X$ are $Y$.

No $X$ is $Y$.

Some $X$ are not $Y$.

There are four possible arrangements of the terms in the premises known as "figures" :

$\begin{array}{cccc}\text { Figure 1 } & \text { Figure 2 } & \text { Figure } 3 & \text { Figure 4 } \\ \mathrm{A}-\mathrm{B} & \mathrm{B}-\mathrm{A} & \mathrm{A}-\mathrm{B} & \mathrm{B}-\mathrm{A} \\ \mathrm{B}-\mathrm{C} & \mathrm{C}-\mathrm{B} & \mathrm{C}-\mathrm{B} & \mathrm{B}-\mathrm{C}\end{array}$

The figural effect is an effect on the form of conclusions, for example, Figure 1 tends to yield conclusions of the form: $A-C$, whereas Figure 2 tends to yield conclusions of the form: $C-A$ (see Dickstein, 1978; Garcia-Madruga, 1982; Johnson-Laird, 1975). For the symmetric figures, 3 and 4 , there are also some weaker effects (García-Madruga, 1982; Iohnson-Laird \& Bara, 1984). According to the model theory, reasoners build a model for each premise and integrate these models, or they can update their model of the first premise with information from the second premise. The direction of the conclusion depends on the position of the end-terms ( $A$ and $C$ ) in the overall model of the premises, which in turn depends on the order in which information enters working memory (Johnson-Laird \& Bara, 1984). The model of the premises in Figure 1 is constructed by adding the model of the second premise to the end of the first premise, because the middle terms are adjacent. Hence, the conclusion will tend to be in the $A$ - $C$ direction. But, in order to make the middle terms adjacent in Figure 2, reasoners must reverse the order of the premises. The resulting model will tend to yield a conclusion in the $C-A$ direction. It follows, in addition, that inferences in Figure 2 should be more difficult than those in Figure 1, because of the need to consider the premises in their opposite order. This prediction was borne out in an experiment in which we used on-line measures of reading time for the second premise. The results showed that processing the second premise took significantly longer in Figure 2 than in Figure 1 (Espino, Santamaria, \& GarciaMadruga, 2000a).

Espino, Santamaría, and García-Madruga (2000b) carried out a series of experiments using a new technique to measure the mental activation of the terms when the participants read the premises and made inferences from them. Their task was to decide whether or not words had occurred in the formulation of the problem. These words included those that corresponded to the terms of the premises: A, B, and C. The time they spent responding to the question about one of the terms indicated its activation or accessibility, and revealed some aspects of its representation in memory during syllogistic reasoning. The most striking result occurred after the participants had read the second premise. For Figure I $(\mathrm{A}-\mathrm{B} ; \mathrm{B}-\mathrm{C})$, the inost active term was $C$, which is the end-term of the second premise and the most recent term to be represented in the model of the premises. In contrast, for Figure $2(B-A, C-B)$, the most active term was $A$, which is the end-term of the first 
premise, but is the most recent term to be represented in the model granted that the premises are processed in reverse order. The results of this study were the subject of a debate with Mike Oaksford in Thinking and Reasoning (Oaksford, 2001; Santamaría, Espino, \& García-Madruga, 2001). But, they corroborate the model theory's prediction that reasoners tend to consider the premises of syllogisms in Figure $l$ in the order in which they are stated, whereas they tend to reverse the order of the premises in Figure 2.

\section{Logical Structure and Believability in Double Conditionals}

Santamaría, García-Madruga, and Johnson-Laird (1998) examined reasoning from double conditionals such as:

If Concha studies then she passes the exam.

If Concha passes the exam then she finishes the course.

We manipulated the figure of the premises as in the study of syllogisms, using the four different figures shown in the previous section. We also manipulated the believability of the two forms of putative conditional conclusion. The preceding premises are in the $\mathrm{A}-\mathrm{B}, \mathrm{B}-\mathrm{C}$ figure, and the $\mathrm{A}-\mathrm{C}$ conclusion is valid and believable:

If Concha studies then she finishes the course whereas the converse conclusion $(C-A)$ is invalid and unbelievable:

If Concha finishes the course then she studies.

With different contents, the same figure yields opposite effects. For example, from the following premises:

If Marta is hungry then she eats an aftemoon snack. If Marta eats an afternoon snack then she has a light dimer.

the $\mathrm{A}-\mathrm{C}$ conclusion:

If Marta is hungry then she has a light dinner is valid but unbelievable, whereas the $\mathrm{C}-\mathrm{A}$ conclusion:

If Marta has a light dinner then she is hungry is invalid but believable.

We carried out three experiments in which we measured both the validity of the conclusions that the participants drew and the response latencies. Participants drew valid conciusions more often and more rapidly when they were believable than when they were unbelievable. Likewise, inferences in Figure 1 were easier and faster than inferences in Figure 2. Conditionals in Figure 1 (If $A$ then $B$; If $B$ then $C)$ yield the following mental models:

$$
\text { a b c }
$$$$
\text { … }
$$

If the explicit model is believable, participants will draw the valid conclusion, If $A$ then $C$, with no difficulty. But, if the model is unbelievable, some participants will tend to reject it or try to confirm the invalid but believable conclusion, if $C$ then $A$. Conditionals in Figure 2 (If $B$ then $A$; If $C$ then $B$ ), call for reasoners to construct their mental models starting with the second premise:

$$
\begin{array}{lll}
c & b & a \\
\ldots &
\end{array}
$$

As the accuracy of the responses and their latencies showed, the process was more difficult and slower.

\section{Counterfactual conditionals}

Counterfactual conditionals have provided a source of information to evaluate theories of reasoning and of cognitive development (Riggs \& Peterson, 2000). According to the model theory (Johnson-Laird \& Byrne, 1991), a conditional, such as:

If Carlos had played then the team would have won can be interpreted counterfactually, that is, as implying that Carlos did not play and the team did not win, but in the case contrary to the facts in which Carlos had played the team would have won. (Such conditionals also have an interpretation in which the speaker does not know whether or not Carlos played, but asserts that had he played the team would have won.) The counterfactual interpretation calls for two explicit mental models, one representing the facts and the other the counterfactual possibility:

Facts:

$\neg$ Carlos played. $\neg$ The team won. Counterfactual possibilities:

Carlos played. The team won. $\cdots$

These models immediately yield both the MP and the MT inferences, and so once again the normal difference in difficulty between them, which we described earlier, should disappear with counterfactual conditionals. Ruth Byme and her colleagues corroborated this prediction in an experiment in which the participants drew their own conclusions (Byme \& Tasso, 1999). Moreno-Rjos, García-Madruga, and Byrne (2002) have also replicated the result using an evaluation task. These authors also used a type of conditional known as a semifactual:

If Carlos had played, the team would still have won.

It calls for the following two mental models:

Facts:

$\neg$ Carlos played. The team won.

Counterfactual possibilities:

Carlos played. The team won

It is moot point whether any other possibility is compatible with the truth of the assertion, but presumably its truth allows, say, that if Juan had played the team would have lost, and so such possibilities are represented by the implicit model. Table 9 summatizes the mental models for factual, counterfactual, and semifactual conditionals.

The models for the semifactual conditional should impede all the standard conditional inferences except for MP. For example, the premises for MT:

If Carlos had played, the team would still have won.

In fact, the team did not win.

seem almost self-contradictory. They do not permit the conclusion:

Carlos did not play. 
because it corresponds to the factual possibility. The truth of the minor premise calls for fleshing out the implicit model and for the introduction of some new factor, such as that Juan played. Hence, the theory predicts that reasoners are more likely to respond that there is no valid conclusion. For DA, the categorical premise Carlos did not play corresponds to the facts of the matter, and reasoners should respond: the team won. This inferences is otiose, however, because it does correspond to the facts of the matter. For $\mathrm{AC}$, the categorical premise the team won is compatible with either of the two mental models, which yield opposing conclusions, and so those participants who keep both models in mind should respond that there is no valid conclusion.

The results of the experiment showed that MP and MT were equally likely to be drawn from a counterfactual conditional, whereas for both factual and semifactual conditionals, MP was much more likely to be drawn than MT. For semifactuals, most responses to $M T$ and AC were that there was no valid conclusion, but reasoners did draw the conclusion from DA corresponding to the facts of the matter. The latencies of the responses replicated the results of the accuracy measure. Likewise, the reading times for the counterfactual and semifactual conditionals were longer than those of the factual conditionals. This latter result fits the assumption that reading counterfactual and semifactual conditionals leads to the construction of two explicit mental models, whereas reading factual conditionals leads to the construction of only one explicit mental model. The same factor accounts for the lower frequency of inferences from counterfactual and semifactual conditionals than from factual conditionals.
Moreno-Ríos and García-Madruga (in press) have replicated the results with semifactual and factual conditionals in a developmental study of four age groups: 7, 11, and 14 year-old children, and adults. The developmental pattern for factual conditionals corroborated the one in the literature (Barrouillet, Grosset, \& Lecas, 2000; Delval \& Carretero, 1979; Evans, Newstead, \& Byrne, 1993): a conjunctive interpretation (one model) in the first years, a subsequent biconditional interpretation (two models), and, lastly, the conditional interpretation (three models) only in older children and adults. The model theory provides a simple explanation of these results: Individuals develop a greater capacity of working memory, and so can flesh out models in the order of their importance. With semifactual conditionals, the participants of all ages showed a lower frequency of acceptance of inferences. But, with increasing age, the children's performance pattern approached that of adults. The youngest children already blocked the MT inference and, somewhat later, they were impeded in DA. Only adolescents were able to block AC, presumably noticing that it led to two incompatible models. These results suggest that young children can build multiple models, but they need a greater working memory capacity to compare the information in the models.

\section{General Conclusions}

Three main conclusions emerge from our studies. The first conclusion is that the results corroborate our extension of the model theory. One change in the theory from its earlier formulation (Johnson-Laird \& Byrne, 1991) is the

Table 9

The Mental Models for Three Sorts of Conditional, and the Inferences that can be Directly Derived from them Without Fleshing them out into Fully Explicit Models

Initial Models Inferences directly derived from the explicit mental models

\section{Factual}

Fact:

$\mathrm{p} \quad \mathrm{q}$

$q$

p; theretore, q.

(MP)

$q$; therefore, $p$.

Counterfactual

Fact:

$\begin{array}{rrr}\neg \mathrm{p} & & \neg \mathrm{q} \\ \mathrm{p} & & \mathrm{q}\end{array}$

not $\mathbf{p}$; therefore, not $\mathbf{q}$.

(DA)

Counterfact:

$q$

not $q$; therefore, not $p$.

$p$; therefore, $q$.

$q$; therefore, $p$.

Semifactual
Fact:
Counterfact:

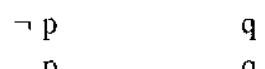

q

not $p$; therefore, $q$.

$p$; therefore, $q$ -

Note MP = Modus Ponens $\mathrm{AC}=$ Affirming the consequent; $\mathrm{DA}=$ Denying the Antecedent; MT $=$ Modus Tollcns. 
introduction of strategic considerations. Different individuals tend to develop different strategies, which influence the order in which they process the premises and the conclusion if one is given for evaluation. They may also affect the way individuals integrate information into models, as we suggested in discussing the results of the studies with multiple conditionals and with the four sonts of conditional. This modification may appear to weaken the theory in that it makes it harder to refute. But, in fact, the mechanism underlying the different strategies appears to depend on mental models, and that is why number of models remains a cornerstone of the theory.

The second conclusion concerns number of models. If a study had shown that the difficulty of a set of inferences ran counter to number of models, then the model theory would have been refuted. Rips's $(1990,1994)$ studies merely failed to find a predicted effect of number of models: Inferences based on conjunctions (one model) were no easier than inferences based on disjunctions (two or three models). This result threatened the theory (and, so it seemed to us, rule theories too). But, as our studies have shown, when reasoners have to generate their own conclusions, the model theory's predictions were vindicated. Rips's (1990) procedure was not sufficiently sensitive, or elicited a ceiling effect, to detect the effect of number of models. Likewise, our results with inferences based on multiple conditionals also corroborated the effect of number of models.

Our third conclusion concerns the way in which to develop the model theory. In general, with the introduction of a new sentential connective, such as unless, the model theorist's task is to formulate its semantics, and the set of mental models (of possibilities) to which it refers. Thereafter, the general mechanisms of the theory apply: The same processes are used to construct models, to formulate conclusions, and to ensure that they are valid.

\section{References}

Barrouillet, P., Grosset, N., \& Lecas, J,-F. (2000). Conditional reasoning by mental models: Chronometric and developmental evidence. Cognition, 75, 237-266.

Braine, M.D.S. (1978). On the relation between the natural logic of reasoning and standard logic. Psychological Review, 85, 121.

Braine, M.D.S. (1990). The " natural logic" approach to reasoning. In W.F. Overton (Ed.), Reasoning, necessity and logic: Developmental perspectives (pp. 135-157). Hillsdale, NJ: Erlbaum.

Braine, M.D.S., \& O'Brien, D.P. (1991). A theory of If; A lexical entry, reasoning program, and pragmatic principles. Psychological Review; 98, 182-203.

Braine, M.D.S., Reiser, B.J., \& Rumain, B. (1984). Some empirical justification for a theory of natural propositional reasoning. In G.H. Bower (Ed.), The psychology of learning and motivation. Vol. 1. (pp. 313-371). New York: Academic Press.
Byme, R.M.J., \& Johnson-Laird, P.N. (1989). Spatial reasoning. Joumal of Memory and Language, 28, 564-575.

Byrne, R.M.J., \& Tasso, A. (1999). Deductions from factual, possible and counterfactual conditionals. Memory \& Cognition, $27,726-740$.

Carriedo, N., García-Madruga, J., Gutiérrez, F., \& Moreno, S. (1999, November). How does content affect 'unless' conditional reasoning? Proceedings of the European Conference on Cognitive Science (pp. 271-277). Sienna, Italy.

Delval, J.A., \& Carretero, M. (1979). La adquisición de las conectivas proposicionales. In J. A. Delval (Ed.), Lecturas de psicología del niño. (Vol.2, pp. 178-194). Madrid: Alianza.

Dickstein, L.S. (1978). The effects of figure on syllogistic reasoning. Memory and Cognition, 6, 76-83.

Espino, O., Santamaría, C., \& García-Madruga, J.A. (2000a). Activation of end-terms in syllogistic reasoning. Thinking and Reasoning, 6, 67-89.

Espino, O., Santamaría, C., \& García-Madruga, J.A. (2000b). Figure and difficulty in syllogistic reasoning. Current Psychology of Cognition, 19, 417-428.

Evans, J.St.B.T. (1977). Linguistic factors in reasoning. Quarterly Joumal of Experimental Psychology, 29, 297-306

Evans, J.St.B.T. (1993). The mental model theory of conditional reasoning: Critical appraisal and revision. Cognition, 48, 1-20.

Evans, J.St.B.T., \& Beck, M.A. (1981). Directionality and temporal factors in conditional reasoning. Current Psychological Research, 1, 111- 120.

Evans, J.St.B.T., Clibbens, J., \& Rood, B. (1995). Bias in conditional inference: Implications for mental models and mental logic. Quarterly Journal of Experimental Psychology, $48 A, 644-670$.

Evans, J.ST.B.T., Newstead, S.E., \& Byme, R.M.J. (1993). Human reasoning: The psychology of deduction. Hove, UK: Erlbaum.

Evans, J.ST.B.T \& Over, D.E. (1996). Rationality and reasoning. Hove, UK: Psychology Press.

Fillenbaum, S. (1976). Inducements: On phrasing and logic of conditional promises, threats and warnings. Psychological Research, 38, 231-250.

Fillenbaum, S. (1986). The use of conditionals in inducements and deterrents. In E.C. Traugott, A. ter Meulen, J.S. Reilly, \& C.A. Ferguson (Eds.), On conditionals (pp. 179-195). Cambridge, UK: Cambridge University Press.

García-Madruga, J.A. (1982). Un estudio sobre el efecto de la figura en el razonamiento silogístico. Estudios de Psicología, 11, 23-32.

García-Madruga, J.A., Carriedo. N., Moreno, S., Gutiérrez, F., \& Schaeken, W. (2002), Reasoning from different conditional statements: Unless versus if then, if not then and only if. Manuscript submitted for publication.

García-Madruga, J.A., Moreno Ríos, S., Carriedo, N., \& Gutiérrez, F. (1999). Task, premise order and strategies in Rips's conjunction-disjunction and conditionals problems. In $\mathrm{G}$. D'Ydewalle, W. Schaeken, A. Vandierendonk, \& G. De Vooght (Eds.), Deductive reasoning and strategies (pp. 49-71). Mahwah, NJ: Erlbaum. 
García-Madruga, J.A., Moreno, S., Carriedo, N. \& Gutiértez, F. (2000). Time measures in Rips's problems. In J,A. GarcíaMadruga, N. Carriedo, \& M..J. González Labra (Eds.), Mental models in reasoning (pp. 213-226). Madrid: UNED.

García-Madruga, J.A., Moreno, S., Carriedo, N., Gutiérrez. F., \& Johnson-Laird, P.N. (2001). Are conjunctive inferences easier than disjunctive inferences? A comparison of rules and models. Quarterly Journal of Experimental Psychology; 54 A, 613632.

Geis, M. L. (1973). If and unless. In B. B. Kachru, R. B. Lees, Y. Malkiel, A. Pietrangeli, \& S. Saporta (Eds.), Issues in linguistics (pp. 231-253). Chicago, IL: University of Illinois Press.

Giroto, V., Mazzoco, A., \& Tasso, A. (1997). The effect of premise order in conditional reasoning: A test of the mental model theory. Cognition, 63, 1-28.

Gutiérrez, F., García-Madruga, J.A., Carriedo, N., \& Moreno, S. (2000). Reasoning with multiple conditionals. When do reasoners construct mental models? In J.A. Garcia-Madruga, N. Carriedo, \& M.J. González Labra (Eds.), Mental models in reasoning. (pp. 283-297). Madrid: UNED.

Gutiérrez Martínez, F., García-Madruga, J.A., Johnson-Laird, P.N., \& Carriedo López, N. (2002). Razonamiento con condicionales múltiples. La perspectiva de los modelos mentales. Anuario de Psicología, 33, 2.24.

Johnson-Laird, P.N. (1975). Models of deduction. In R.J Falmagne (Ed.), Reasoning: Representation and process (pp. 7-54). Springdale, NJ; Ertbaum.

Johnson-Laird, P.N. (1983). Mental models: Towards a cognitive science of language, inference, and consciousness. Cambridge, UK: Cambridge University Press.

Johnson-Laird, P.N. (2000). The current state of the mental model theory. In J.A. García-Madruga, N. Carriedo. \& M.J. González Labra (Eds.), Mental models in reasoning (pp. 16-40). Madrid: UNED.

Johnson-Laird, P.N., \& Bara, B.G. (1984). Syllogistic inference. Cognition, 16, 1-6.1.

Johnson-Laird, P.N., \& Byme, R.M.J. (1991). Deduction. Hillsdale, NJ: Erlbaum.

Johnson-Laird, P.N., \& Byrne, R. M. J. (in press). Conditionals: A theory of meaning, pragmatics and inference. Psychological Review.

Johnson-Laird, B.N., Byme, R., \& Schaeken, W. (1992). Propositional reasoning by model. Psychological Review, 99, 418-439.

Legrenzi, P., Girotto, V., \& Johnson-Laird, P.N. (1993). Focussing in reasoning and decision making. Cognition, 49, 37-66.
Moreno-Ríos, S., \& García-Madruga, J.A. (in press). El desarrollo del razonamiento sobre to que podría haber ocurrido: condicionales indicativos y subjuntivos. Infancia y Aprendizaje.

Moreno-Ríos, S., García-Madruga, J.A., \& Byrne, R.M. (2002). The effects of linguistic mood on "if": semifactual and counterfactual conditionals. Manuscript submitted for publication.

Oaksford, M. (200 [). Language processing, activation and reasoning: A reply to Espino, Santamaria and García-Madruga. Thinking \& Reasoning. 7, 205-208.

Polk, T.A., \& Newell, A. (1995). Deduction as verbal reasoning. Psychological Review, 102, 533-566.

Quine, W.V. (1972). Methods of logic ( $3^{\text {rd }}$ ed.). New York; Holt, Rinehart, \& Winston.

Reichenbach, H. (1947). Elements of symbolic logic. New York: Free Press.

Riggs, K.J., \& Peterson, D.M. (2000). Counterfactual thinking in pre-school children: Mental state and causal inferences. In P. Mitchell \& K.J. Riggs (Eds.), Children's reasoning and the mind (pp. 87-99). Hove, UK: Psychology Press.

Rips, L.J. (1983). Cognitive processes in propositional reasoning. Psychological Review, 90, 38-71.

Rips, L.J. (1990). Paralogical reasoning: Evans, Johnson-Laird, and Byrne on liar and truth-teller puzzles. Cognition, 36, 291-314.

Rips, L.J. (1994). The Psychology of proof: Deductive reasoning in human reasoning. Cambridge, MA: MIT Press.

Santamaría, C., Espino, O., \& Garcia-Madruga, J.A. (2001). Theories of reasoning and the representational level: A reply to Oaksford. Thinking and reasoning, 7, 209-213.

Santamaría, C., García-Madruga, J.A., \& Johnson-Laird, P.N, (1998). Reasoning from double conditionals: The effects of logical structure and believability. Thinking and Reasoning, 4, 97-122.

Schaeken, W., Garcia-Madruga, J.A., \& d'Ydewalle, G. (1997). Unless recsoning. Unpublished paper.

Van der Henst, J-B., Yang, Y., \& Johnson-Laird, P.N. (in press). Strategies in sentential reasoning. Cognitive Science.

Wright, P., \& Hull, A.J. (1986). Answering questions about negative conditionals. Joumal of Memory and Language, 25, 691-709.

Wright, P., \& Hull, A. J. (1988). Reading to do: Creating contingent action plans. British Journal of Psychology, 79, 187-211.

Received March 11, 2002

Revision received June 5, 2002

Accepted June 25, 2002 


\section{ORDER FORM}

\section{THE SPANISH JOURNAL OF PSYCHOLOGY}

Please enter my annual subscription (2002) at the following rate (singles issues half price):

$\square$ Individual Rate $\square$ Institutional Rate

$\begin{array}{lllr}\square \text { Europe } & 20 \text { euros } & \square \text { Europe } & 30 \text { euros } \\ \square \text { Other Countries } & 25 \text { euros } & \square \text { Other Countries } & 40 \text { euros }\end{array}$

Method of Payment

$\square$ Bank money order payable to:

The Spanish Journal of Psychology

Banco Central Hispano

Somosaguas, 28223 - Madrid (Spain)

To account No: $0049 / 2197 / 52 / 2414025461$

\section{Credit Card}

$\square$ Visa $\square$ American Express

$\square$ Mastercard $\square$ Diner's Club

Card No::

Expiry Date:

$. . . \ldots \ldots \ldots . . . . .$.

Signature:

Date: $/ \ldots \ldots+\ldots \ldots$

\section{Ship to:}

Name:

Address:

Postal code/Zip: City/State:

Country:

Send this order form to: Servicio de Publicaciones

Universidad Complutense

Isaac Peral $s / \mathrm{n}$

E-28040 Madrid (Spain) 
